\title{
A novel histone deacetylase pathway regulates mitosis by modulating Aurora B kinase activity
}

\author{
Yun Li, ${ }^{1}$ Gary D. Kao, ${ }^{2}$ Benjamin A. Garcia, ${ }^{3}$ Jeffrey Shabanowitz, ${ }^{3}$ Donald F. Hunt, ${ }^{3,4}$ Jun Qin, ${ }^{5}$ \\ Caroline Phelan, ${ }^{1}$ and Mitchell A. Lazar ${ }^{1,6}$ \\ ${ }^{1}$ Division of Endocrinology, Diabetes, and Metabolism, Department of Medicine, Department of Genetics, and the Institute \\ for Diabetes, Obesity, and Metabolism, University of Pennsylvania School of Medicine, Philadelphia, Pennsylvania 19104, \\ USA; ${ }^{2}$ Department of Radiation Oncology, University of Pennsylvania School of Medicine, Philadelphia, Pennsylvania \\ 19104, USA; ${ }^{3}$ Department of Chemistry, University of Virginia, Charlottesville, Virginia 22904, USA; ${ }^{4}$ Department of \\ Pathology, University of Virginia, Charlottesville, Virginia 22904, USA; ${ }^{5}$ Department of Molecular and Cellular Biology, \\ Baylor College of Medicine, Houston, Texas 77030, USA
}

\begin{abstract}
Histone deacetylase (HDAC) inhibitors perturb the cell cycle and have great potential as anti-cancer agents, but their mechanism of action is not well established. HDACs classically function as repressors of gene expression, tethered to sequence-specific transcription factors. Here we report that HDAC3 is a critical, transcription-independent regulator of mitosis. HDAC3 forms a complex with A-Kinase-Anchoring Proteins AKAP95 and HA95, which are targeted to mitotic chromosomes. Deacetylation of $\mathrm{H} 3$ in mitosis requires AKAP95/HA95 and HDAC3 and provides a hypoacetylated H3 tail that is the preferred substrate for Aurora B kinase. Phosphorylation of H3S10 by Aurora B leads to dissociation of HP1 proteins from methylated H3K9 residues on mitotic heterochromatin. This transcription-independent pathway, involving interdependent changes in histone modification and protein association, is required for normal progression through mitosis and is an unexpected target of HDAC inhibitors, a class of drugs currently in clinical trials for treating cancer.
\end{abstract}

[Keywords: AKAP; Aurora; HDAC; histone code; mitosis]

Supplemental material is available at http://www.genesdev.org.

Received June 2, 2006; revised version accepted July 28, 2006.

Covalent modifications of the core histones at their $\mathrm{N}$ terminal tails are involved in many nuclear processes including DNA packaging, DNA replication, and transcriptional regulation, as well as chromosome condensation and segregation during mitosis. Specific patterns of histone modifications regulate protein-protein interactions and protein access to DNA (Turner 2000; Jenuwein and Allis 2001). In particular, phosphorylation of histone 3 (H3) on Ser 10 (S10) is a well-established, evolutionarily conserved mitotic event, observed in ciliate, yeast, worm, and vertebrates (Gurley et al. 1973; Paulson and Taylor 1982; Hendzel et al. 1997; Cobb et al. 1999; Hsu et al. 2000). Mutation of H3S10 in Tetrahymena leads to both chromosome condensation and segregation defects (Wei et al. 1999).

The serine/threonine kinase Aurora B phosphorylates H3S10, a mechanism that is also evolutionarily conserved (Richie and Golden 2005). Depletion of Aurora B in Drosophila cells and Caenorhabditis elegans results

\footnotetext{
${ }^{6}$ Corresponding author.
}

E-MAIL lazar@mail.med.upenn.edu; FAX (215) 898-5408.

Article is online at http://www.genesdev.org/cgi/doi/10.1101/gad.1455006. in reduced H3S10 phosphorylation and is associated with impaired chromosome condensation and segregation (Adams et al. 2001; Giet and Glover 2001). In mammalian cells, phosphorylation of H3S10 by Aurora B dissociates HP1 from heterochromatin during mitosis (Fischle et al. 2005; Hirota et al. 2005). While both Aurora A and B can phosphorylate H3S10 in cell-free experiments, in intact cells only Aurora B colocalizes with the phosphorylated H3S10 during the early stage of mitosis (Crosio et al. 2002). Consistent with its central role in mitosis, impairment of Aurora B activity results in defects in chromosome condensation, segregation, and cellular division (Hsu et al. 2000; Giet and Glover 2001; Goto et al. 2002; Meraldi et al. 2004). Recently, Aurora B has been implicated as mediator of a "methphos switch" whereby Aurora-dependent phosphorylation of H3S10 leads to the dissociation of the methyllysine-binding protein heterochromatin protein 1 (HP1) from chromatin during mitosis (Fischle et al. 2005; Hirota et al. 2005).

In contrast to the links between histone phosphorylation and mitosis, the role and regulation of histone acetylation during mitotic progression have been less 
well studied. Acetylation of core histone tails by histone acetyltransferases (HATs) is a paradigm for transcriptional activation and is reversed by histone deacetylases (HDACs) (Grunstein 1997; Wade et al. 1997; Cheung et al. 2000b). Notably, hypoacetylation of histones has also been found during mitosis. The acetylation of histones begins to decrease during the early stages of mitosis, is absent in metaphase and anaphase, then gradually increases in the late mitotic phase (Marian and Wintersberger 1982; Jeppesen et al. 1992; Kruhlak et al. 2001; Chen et al. 2005; Valls et al. 2005; Nishiyama et al. 2006).

A role for histone deacetylation during mitosis has been further suggested by the cell cycle effects of HDAC inhibitors (Marks et al. 2001; Wong et al. 2005). HDAC inhibitors have attracted considerable interest in the clinic, with early studies suggesting anti-tumor efficacy for a range of malignancies including $\mathrm{T}$-cell lymphoma (Marks et al. 2001; Zhang et al. 2005a). However, the molecular mechanisms of their anti-tumor effects are not well established. Most investigators have focused on transcriptional mechanisms, and in particular on the induction of the cell cycle inhibitor p21, but while HDAC inhibitors globally increase histone acetylation, the level of transcription is altered in only $2 \%-5 \%$ of all expressed genes (Della Ragione et al. 2001; Johnstone and Licht 2003). Moreover, transcriptional mechanisms do not explain the dramatic mitotic effects of HDAC inhibition, which impairs mitotic progression with associated defects in chromosome condensation, segregation, and kinetochore assembly (Qiu et al. 2000; Sandor et al. 2000; Shin et al. 2003; Warrener et al. 2003; Mikhailov et al. 2004; Robbins et al. 2005).

HDAC3 is widely expressed, highly regulated, and mediates its function through protein-protein interactions (Emiliani et al. 1998; Guenther et al. 2002; Yang et al. 2002). Immature HDAC3 is folded by the TCP-1 ring complex (TRiC) before interacting with the transcriptional corepressor protein N-CoR (nuclear receptor corepressor) and SMRT (silencing mediator for retinoid and thyroid hormone receptors) (Li et al. 2000; Guenther et al. 2002). N-CoR and SMRT serve as activating cofactors for HDAC3 enzymatic activity (Guenther et al. 2001; Zhang et al. 2002). HDAC3 activity is also regulated through phosphorylation by casein kinase II and dephosphorylation by protein phosphatase 4 (Zhang et al. 2005b). HDAC3 is required for transcriptional repression by nuclear hormone receptors (Ishizuka and Lazar 2003, 2005) and also suppresses the transcriptional potential of other transcription factors including YY1, GATA-2, and TFII-I (Ozawa et al. 2001; Yao et al. 2001; Wen et al. 2003). HDAC3 knockdown was recently shown to increase cells in G2/M phase in human colon cancer cells (Wilson et al. 2006), but the molecular mechanism of this effect is unknown.

Here we report that HDAC3 forms a complex with A-Kinase Anchor Protein 95 (AKAP95) and its relative Homologous to AKAP95 (HA95) in mitotic cells. AKAP95 and HA95 have been previously shown to be recruited to mitotic chromosomes and involved in mi- totic progression, but their mechanism of action is obscure (Collas et al. 1999; Orstavik et al. 2000; Steen et al. 2000). We find that HDAC3, along with AKAP95/HA95, is required for normal mitotic progression, and that both HDAC3 and AKAP95/HA95 are essential for global histone deacetylation that occurs during mitosis. Unexpectedly, HDAC3 and AKAP95/HA95 are also required for maximal phosphorylation of H3S10 in mitosis. Reduction in HDAC3 level and pharmacological inhibition of HDAC activity leads to increased histone acetylation, decreased H3S10 phosphorylation, and accumulation of cells in mitosis, suggesting that inhibition of HDAC3 is sufficient to explain the cell cycle effects of HDAC inhibitors. The reduced phosphorylation H3S10 can be explained by the observation that the H3S10 kinase activity of Aurora B is dependent on the histone acetylation state, with hypoacetylated histone tails being the preferred substrate. HP1 dissociation from mitotic chromosomes is prevented by knockdown of AKAP95/HA95, selective loss of HDAC3, or pharmacological HDAC inhibitors, demonstrating that the AKAP-HDAC3-Aurora $\mathrm{B}$ axis is upstream of the Aurora B-HP1 "meth-phos switch." This novel pathway explains the changes in histone modifications that occur during mitosis, and suggests that HDAC inhibitors used in cancer treatment target HDAC3 via this nontranscriptional mechanism.

\section{Results}

AKAP95 and HA95 are present in high-molecularweight HDAC3 complexes and interact directly with HDAC3

To explore the biological functions of HDAC3, we purified endogenous proteins that coimmunoprecipitated with Flag-HDAC3 stably expressed in $293 \mathrm{~T}$ cells. Proteins identified through silver staining and mass spectrometry included expected components of HDAC3 complexes including N-CoR, SMRT, TBL1, and GPS2 (Fig. 1A; Guenther et al. 2000; Li et al. 2000; Zhang et al. 2002). An additional band, corresponding to a molecular mass of $\sim 95 \mathrm{kDa}$, was found to contain both AKAP95 and HA95, and further verified by Western analysis (Fig. 1A). To further test the intracellular interaction of AKAP95 with HDAC3, HA-epitope tagged-AKAP95 was expressed in 293T cells, followed by immunoprecipitation with anti-HA antibody. Overexpressed AKAP95 was associated with endogenous HDAC3, as well as endogenous N-CoR (Fig. 1B) and SMRT (data not shown). Endogenous HDAC3 was also reliably detected in immunoprecipitates of endogenous HA95, establishing that the in vivo association of AKAP95/HA95 with HDAC3 was not a result of protein overexpression (Fig. 1C). Moreover, recombinant HDAC3 (Fig. 1D), but not other components of HDAC3 complexes (data not shown), interacted with recombinant AKAP95 and HA95 in vitro, suggesting that AKAP95 and HA95 are recruited to the complex through HDAC3 (Fig. 1D). Activation of HDAC3 by the SMRT deacetylase-activating domain 


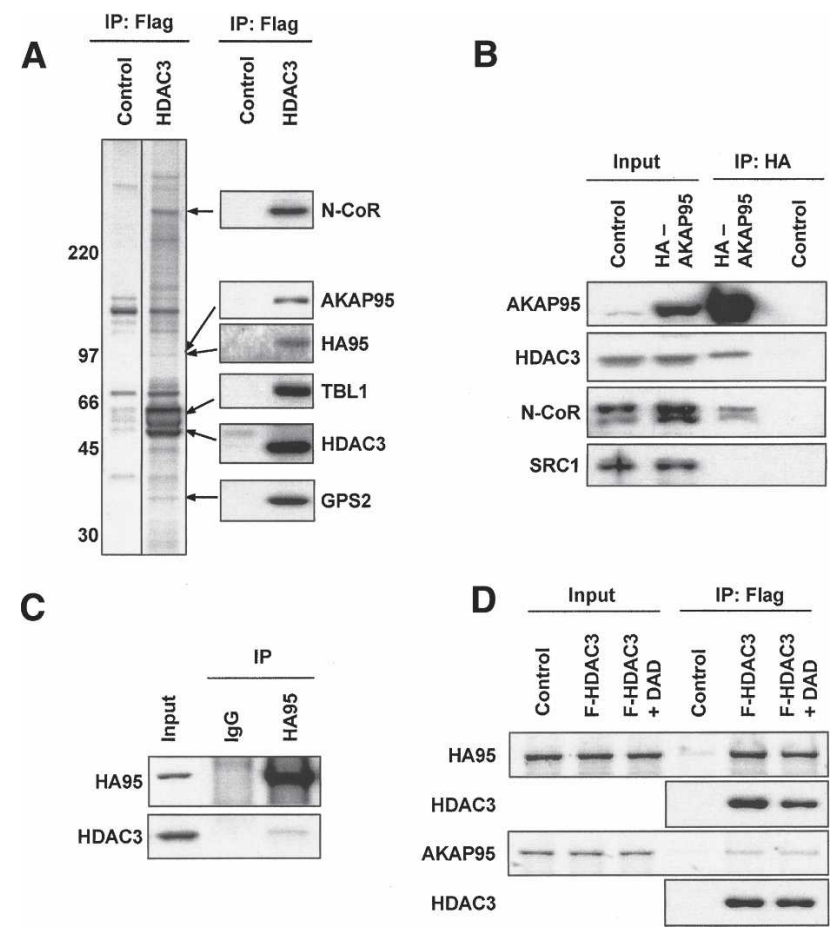

Figure 1. HDAC3 associates with AKAP95 and HA95. (A) Silver staining of proteins associated with Flag-HDAC3 purified from stably transfected $293 \mathrm{~T}$ cells. The $95-\mathrm{kDa}$ protein band was cut and identified by microsequencing and immunoblotting. Other components of HDAC3 complexes were verified by immunoblot. (B) HA-tagged AKAP95 was associated with endogenous HDAC3 corepressor complexes in $293 \mathrm{~T}$ cells. AntiSRC1 served as negative control. All inputs represent $2 \%$ of each total immunoprecipitation in this and all of the figures unless specified. $(C)$ Endogenous HA95 interacts with endogenous HDAC3 in living 293T cells. Whole-cell extracts were immunoprecipitated with anti-HA95 or control antibody prior to immunoblot with anti-HDAC3 and anti-HA95. (D) HDAC3 interacts with AKAP95 and HA95 in vitro. In vitro translated Flag-HDAC3 with or without addition of Gal-SMRT-DAD was mixed with in vitro translated ${ }^{35} \mathrm{~S}$-Met-labeled AKAP95 or HA95 and subjected to immunoprecipitation with anti-Flag followed by autoradiography and Western blot. The empty vector was used for in vitro translation as the control.

(DAD) (Supplementary Fig. 1; Guenther et al. 2001) had little effect on this interaction (Fig. 1D). Taken together, these data demonstrate a physical interaction between AKAP95/HA95 and HDAC3.

Interaction of HDAC3 with AKAP95 and HA95 increases during mitosis

AKAP 95 and HA95 have been previously found to be associated with mitotic chromosomes/Collas et al. 1999; Martins et al. 2000; Steen et al. 2000; Eide et al. 2002), so we next investigated the AKAP-HDAC3 interaction during mitosis. Immunoprecipitation of endogenous HDAC3 with endogenous AKAP95 or HA95 was markedly increased in nocodazole-synchronized cells blocked in G2/M (Fig. 2A). Conversely, coimmunoprecipitation of AKAP95 and HA95 with HDAC3 was also increased in nocodazole-treated cells (Fig. 2B). In contrast, the interaction of HDAC3 with SMRT or N-CoR was essentially unaltered in nocodazole-synchronized cells (Fig. 2B). To exclude the possibility that the increased HDAC3-AKAP95/HA95 interactions were due to drug toxicity, $20 \mathrm{~h}$ of aphidicolin treatment was used to synchronize $293 \mathrm{~T}$ cells at the G1/S transition, then cells were released from aphidicolin treatment for 2 or 12 $\mathrm{h}$ to obtain S-phase- and G2/M-enriched cell populations, respectively. The AKAP-HDAC3 interactions were not increased either in G1/S- or S-phase-synchronized cells (Fig. 2C). However, the interaction between endogenous AKAP95 and HDAC3 was robustly increased in G2/M cells, which have the highest level of H3S10 phosphorylation (Fig. 2C). Using immunofluorescence staining and confocal microscopy, AKAP95 and HDAC3 colocalization was also evident in early mitotic cells compared with cells at interphase (Fig. 2D). To better characterize the mitotic AKAP/HDAC3 complex, HDAC3 complexes prepared from nocodazole-synchronized Flag-HDAC3 stable cells were eluted from immunoprecipitates using Flag peptide then size separated by gel filtration (Fig. 2E). HDAC3 cochromatographed with SMRT in two catalytically active high-molecular-weight complexes ( 1.5-2 $\mathrm{mDa}$ and $\sim 550 \mathrm{kDa}$ ) (Guenther et al. 2000; Li et al. 2000; Zhang et al. 2002), and was also detected in lower-molecular-weight complexes containing the TCP1 $\beta$ subunit of the TRiC chaperone machinery (Guenther et al. 2002). AKAP95 and HA95 were present in the higher-molecular-weight complexes that also contained SMRT (and N-CoR, TBL1, and GPS) (data not shown).

Depletion of AKAP95 and HA95 induces G2/M arrest and mitotic defects

AKAP95 and HA95 have been proposed to have a role in chromosome condensation during mitosis /Collas et al. 1999; Martins et al. 2000; Steen et al. 2000; Eide et al. 2002). We used short-hairpin RNA (shRNA) to knock down AKAP95 and HA95 (Fig. 3A) in order to study their function in the cell cycle. Knockdown of AKAP95 or HA95 individually had modest effects on the cell cycle (data not shown). However, simultaneous depletion of both AKAP95 and HA95 substantially increased the percentage of $\mathrm{G} 2 / \mathrm{M}$ cells as determined by flow-assisted cytometric analysis (FACS) (Fig. 3B). This was, in large part, due to a significantly increased proportion of cells in mitosis (Fig. 3C). Of note, many of these mitotic cells were of quite aberrant morphology, which included incomplete chromosomal condensation or "lagging" chromosomes (Fig. 3D, indicated by the arrowhead in the middle panel, and in higher magnification inset), chromosome segregation defection like a chromosome bridge (Fig. 3D, the right panel), as well as tri- or multipolar mitoses (Fig. 6E [below], bottom right panel). In contrast, 
A

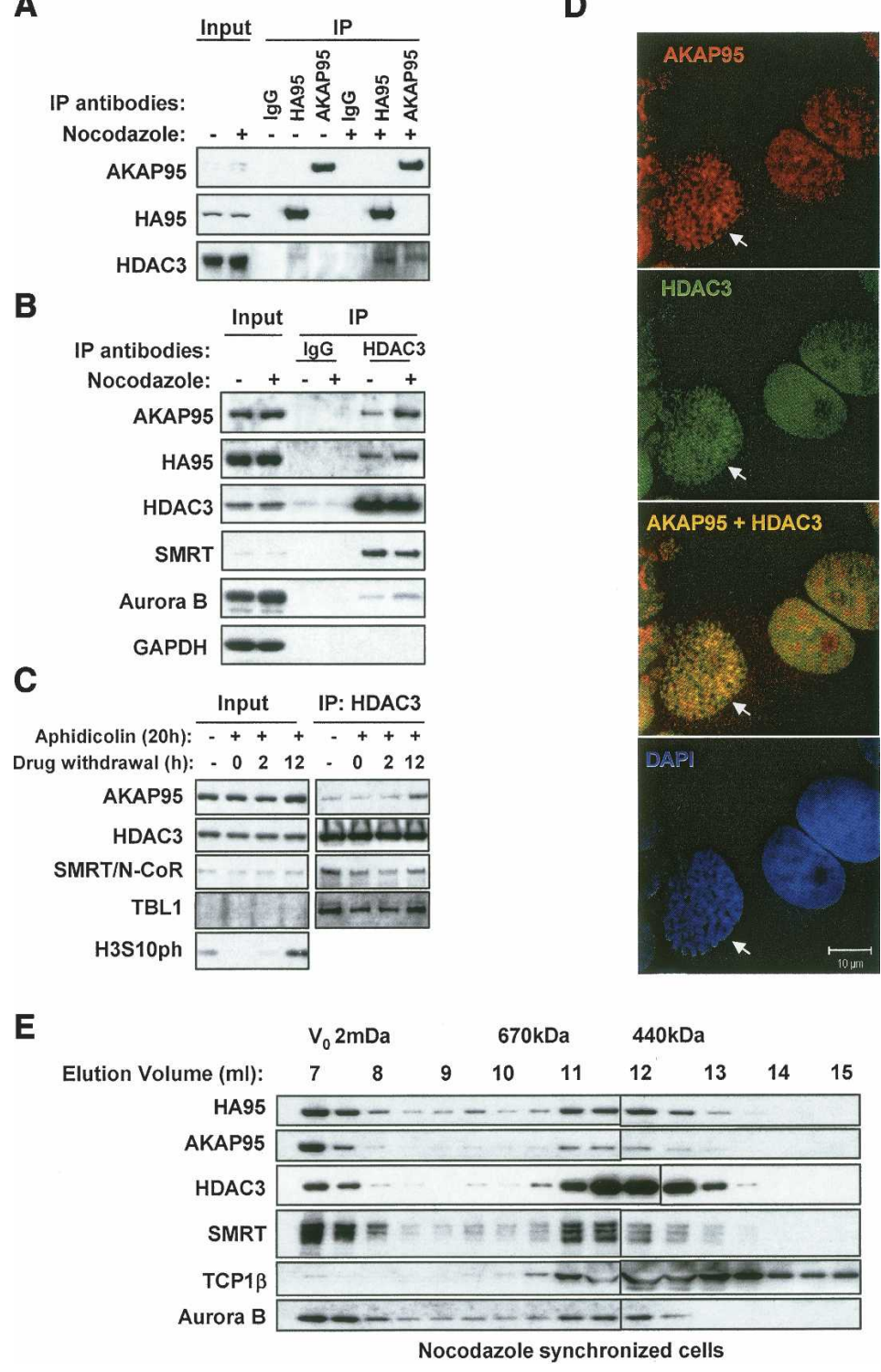

Figure 2. Interaction of HDAC3 with AKAP95 and HA95 increases during mitosis. (A) Extracts from 293T cells synchronized with nocodazole (or not) were immunoprecipitated with antibodies to AKAP95 or HA95, then subjected to Western analysis. (B) Same as $A$, except extracts were immunoprecipitated with antiHDAC3. (C) $293 \mathrm{~T}$ cells were treated with Aphidicolin for $20 \mathrm{~h}$ and then switched to fresh medium to release G1/S-arrested cells. Cells were collected at indicated time points and subjected to immunoprecipitation using anti-HDAC3 and Western blot. $(D)$ Immunofluorescence staining of HeLa cells with anti-HDAC3 (green) and anti-AKAP95 (red), as well as DAPI (blue), using confocal microscopy. The arrow indicates an early mitotic cell with condensed chromosomes. (E) AKAP95 and HA95 were copurified with a high-molecularweight HDAC3 complex. The immunopurified HDAC3 complexes from nocodazole-synchronized Flag-HDAC3 stable cells were fractionated on a Superose 6 column. Fractions from 7-mL to $15-\mathrm{mL}$ elution were analyzed by Western blot with indicated antibodies. few mitoses were found after control shRNA, and these were largely unperturbed (Fig. 3C,D).

Depletion of HDAC3 induces G2/M arrest and mitotic defects similar to those caused by AKAP95/HA95 knockdown

We next tested the effects of HDAC3 knockdown, again via shRNA (Fig. 4A). Knockdown of HDAC3 also substantially increased the percentage of G2/M cells (Fig. $4 \mathrm{~B})$, and mitotic counts again revealed an increased proportion of mitotic cells (Supplementary Fig. 2A). A large proportion of the cells exhibited aberrant mitoses in the absence of HDAC3 (Supplementary Fig. 2B), similar to that seen with knockdown of AKAP95/HA95 (cf. Fig. 3D). Thus, knockdown of HDAC3 or AKAP95/HA95 led to similar impairment of mitotic progression and increased aberrancy of mitotic figures.
HDAC inhibition blocks the cell cycle at G2/M phase in a transcriptional-independent manner

Nonspecific inhibition of HDACs by pharmacological inhibitors has been shown to induce cell cycle arrest beyond prometaphase, in association with mitotic defects reminiscent of the effects of selective loss of HDAC3 demonstrated above (Qiu et al. 2000; Sandor et al. 2000; Shin et al. 2003; Mikhailov et al. 2004; Robbins et al. 2005). Indeed, the nonselective HDAC inhibitor trichostatin A (TSA) caused G2/M arrest both in human MCF7 breast carcinoma cells (Fig. 5A) as well as in human 293T embryonic kidney cells (Fig. 5B), similar to the effect of selective depletion of HDAC3. In contrast, shRNA depletion of the related HDAC1 did not cause mitotic arrest (Supplementary Fig. 3a), suggesting that HDAC3 is a major target by which HDAC inhibitors induce G2/M arrest. The G2/M arrest due to TSA was reversible (Supplementary Fig. 4), and two additional 
A

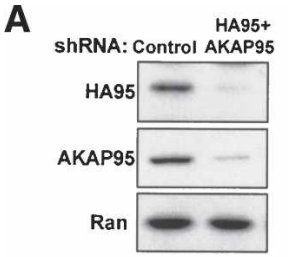

C

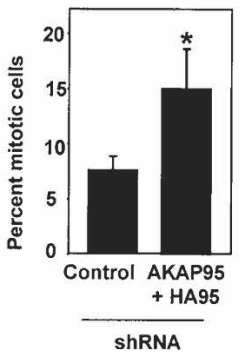

B

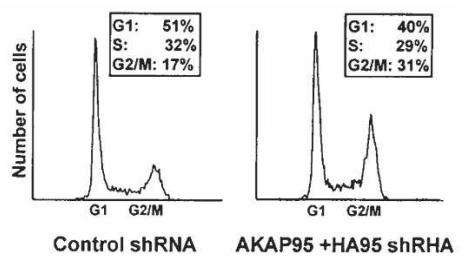

D

Control shRNA
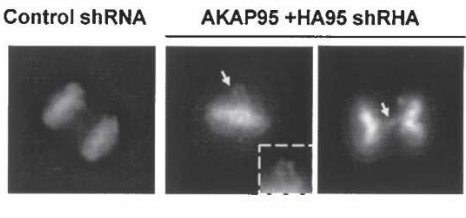

DAPI staining

Figure 3. AKAP95 and HA95 are required for normal G2/M progression. (A) Knockdown of AKAP95 and HA95 in HeLa cells using shRNA. Ran was used as a specificity control. (B) Effect of AKAP95 and HA95 double knockdown on the cell cycle. The DNA content of HeLa cells was determined by FACS, with the resultant histograms as shown. The percentage of cells in each cell cycle phase was calculated by ModFit Software and is presented in the box. Experiments were repeated three times. $(C)$ Mitotic counts of control versus HDAC3 knockdown cells. Error bars represent the standard deviation $(n=3 ; P=0.028)$. (D) DAPI staining of a representative control (left panel) and AKAP95/HA95 double-knockdown cells (middle and right panels). The middle panel shows a mitotic cell with a lagging chromosome (magnified in inset), while the right panel shows a mitotic cell with a chromosome bridge indicated by the arrowhead. The experiments were repeated at least three times with similar results.

nonspecific HDAC inhibitors (sodium butyrate and valproic acid), also blocked the cell cycle in G2/M (Fig. 5C). Importantly, the G2/M arrest due to each of the three HDAC inhibitors was maintained in the presence of actinomycin D (Act D) (Fig. 5C), at a concentration that blocked global transcription by $>90 \%$ (Supplementary Fig. 5). Act $\mathrm{D}$ alone has been reported to induce a partial G1 arrest (Kim et al. 2005), and this was observed in our studies as well (Fig. 5C). These data implied that the major effect of HDAC inhibition on the cell cycle-i.e., G2/M arrest-was not due to effects of these drugs on transcription. This, in turn, suggested that failure to deacetylate histones during mitosis directly impairs on mitosis progression.

Histone deacetylation during mitosis requires HDAC3 and AKAP95/HA95

Our finding of a role for HDAC3 and AKAP95/HA95 in mitosis led us to consider a potential regulatory role for histone deacetylation. Consistent with previous observations (Marian and Wintersberger 1982; Jeppesen et al. 1992; Kruhlak et al. 2001; Valls et al. 2005), we observed that $\mathrm{H} 3$ and $\mathrm{H} 4$ are globally hypoacetylated during mitosis (Fig. 6A). This result was confirmed by quantitative

mass spectrometric analysis of $\mathrm{H} 3$ isolated from nonsynchronized or nocodazole-synchronized HeLa cells (Fig. 6B). Abundance levels of unmodified and trimethylated K9 (Fig. 6B), as well as mono- and dimethylated K9 (data not shown), remain consistent in nonsynchronized and mitotic HeLa cells. However, single acetylation of K9 or K14 and K9/K14 double acetylation dramatically decreased (twofold and sevenfold, respectively) in mitotic cells (Fig. 6B). Similarly, we also noted the decreases in single acetylation of $\mathrm{H} 3 \mathrm{~K} 18$ or K23 as well as K18/K23 dual acetylation in nocodazole-synchronized HeLa cells (Supplementary Fig. 6). These results further confirm that $\mathrm{H} 3$ is globally deacetylated on multiple lysines in mitotic cells.

We next used shRNA to reduce cellular HDAC3 levels and determine whether deacetylation of histones during mitosis is dependent on HDAC3. Indeed, HDAC3 knockdown abolished the global histone deacetylation characteristic of mitotic, nocodazole-treated cells, but had little effect on global histone acetylation in nonsynchronized cells (Fig. 6C). This result indicated that HDAC3 is required for the deacetylation of mitotic histones. Knockdown of N-CoR or SMRT individually did not significantly change the cell cycle progression or histone acetylation (data not shown), suggesting that they redundantly activate HDAC3 in this context. We next used shRNA to knock down AKAP95 and HA95 to address whether the HDAC3-dependent histone deacetylation during mitosis requires these AKAPs. Individual knockdown of AKAP95 or HA95 modestly reduced the deacetylation of $\mathrm{H} 3$ and $\mathrm{H} 4$ during mitosis (data not shown). More strikingly, simultaneous knockdown of AKAP95 and HA95 completely prevented the mitotic deacetylation of H3 and H4 (Fig. 6D). Note that phosphorylation of H3S10, which occurs in mitosis, did not alter our ability to detect $\mathrm{H} 3$ acetylation level (Supplementary Fig. 7).

A

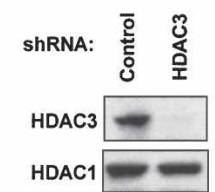

B

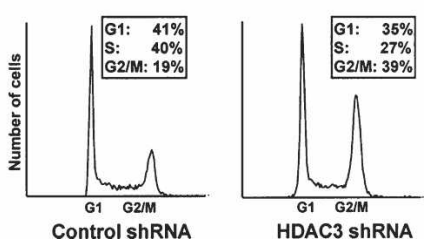

Figure 4. HDAC3 is required for normal G2/M progression. (A) Knockdown of HDAC3 in HeLa cells using shRNA. HDAC1 serves as a specificity control. (B) Effect of HDAC3 knockdown on the cell cycle. The cell cycle distributions of cells expressing control and AKAP95/HA95 shRNA were determined by FACS, with the resultant histograms as shown. The percentage of cells in each cell cycle phase was calculated by ModFit Software and is shown in the boxed legend. The experiments were repeated at least three times with similar results. 
A mcF7 Cells

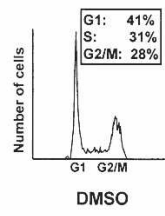

B $293 \mathrm{~T}$ Cells

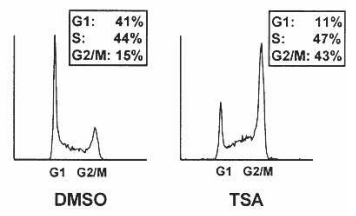

C $^{293 T \text { Cells }}$
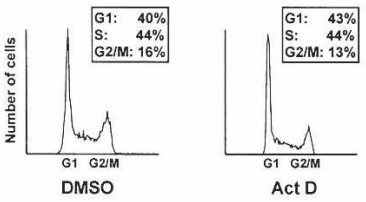

TSA

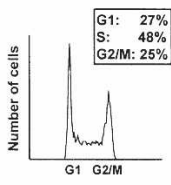

$\mathrm{NaB}$

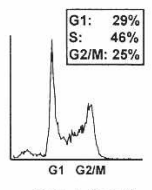

$\mathrm{NaB}+$ Act D

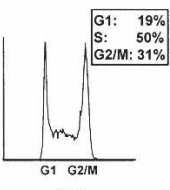

VPA
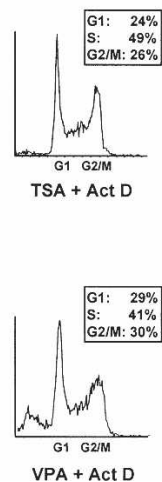

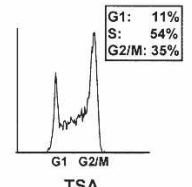

Figure 5. HDAC inhibitors TSA cause G2/M arrest in a transcription-independent manner. (A) FACS of MCF7 cells after TSA treatment $(0.3 \mu \mathrm{M}$ for $10 \mathrm{~h})$. (B) FACS of $293 \mathrm{~T}$ cells after TSA treatment $(0.5 \mu \mathrm{M}$ for $10 \mathrm{~h})$. The percentage of cells in each cell cycle phase was calculated by ModFit Software and presented in the respective boxed legends. (C) FACS of 293T cells after $8 \mathrm{~h}$ of Actinomycin-D (Act D, $1 \mu \mathrm{g} / \mathrm{mL})$, TSA $(0.5 \mu \mathrm{M})$, sodium butyrate $(\mathrm{NaB}, 2.5 \mathrm{mM})$, or VPA $(16 \mathrm{mM})$ treatment, or a combination of Act-D with each HDAC inhibitor.

\section{HDAC3 and AKAP95/HA95 are required for normal phosphorylation of $\mathrm{H} 3$ during mitosis}

H3S10 phosphorylation is a mitotic marker, and therefore should increase in HDAC3- or AKAP95/HA95-depleted cells that contain numbers of mitotic cells. Paradoxically, however, phosphorylation of $\mathrm{H} 3 \mathrm{~S} 10$ was actually reduced when HDAC3 or AKAP95/HA95 levels were depleted (Fig. 6C,D). Immunofluorescence analysis of AKAP95/HA95 double-knockdown HeLa cells also revealed marked reduction in H3 S10 phosphorylation within mitotic nuclei (Fig. 6E). These data are consistent with recent reports that TSA treatment decreased phosphorylation of $\mathrm{H} 3 \mathrm{~S} 10$ in cancer cells (Dowling et al. 2005; Robbins et al. 2005). Indeed, we confirmed that TSA treatment reduced H3S10 phosphorylation in MCF7 breast cancer cells (Fig. 6F) despite increased the number of cells in G2/M (see Fig. 5A). A similar dissociation between $\mathrm{H} 3 \mathrm{~S} 10$ phosphorylation and the percentage of G2/M-arrested cells after TSA treatment was observed in $293 \mathrm{~T}$ cells (data not shown). These results suggest an unanticipated relationship between AKAP95/ HA95-HDAC3-dependent histone deacetylation and the mitosis-associated phosphorylation of H3S10.

Histone acetylation is inversely correlated with H3S10 phosphorylation in cells

The hypothesis that phosphorylation of H3S10 occurs mainly on hypoacetylated histone during mitosis was tested in 293T cells treated with nocodazole for $6 \mathrm{~h}$ to partially enrich the mitotic cells. Chromosome-bound histones were isolated by acid extraction, and the histones were incubated with anti-acetylated $\mathrm{H} 3(\mathrm{H} 3 \mathrm{ac})$ an-

A
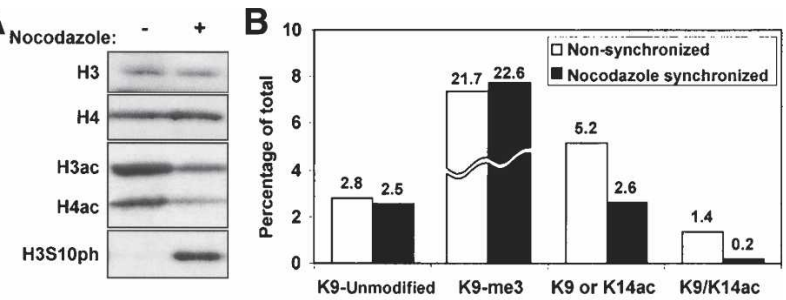

C

D

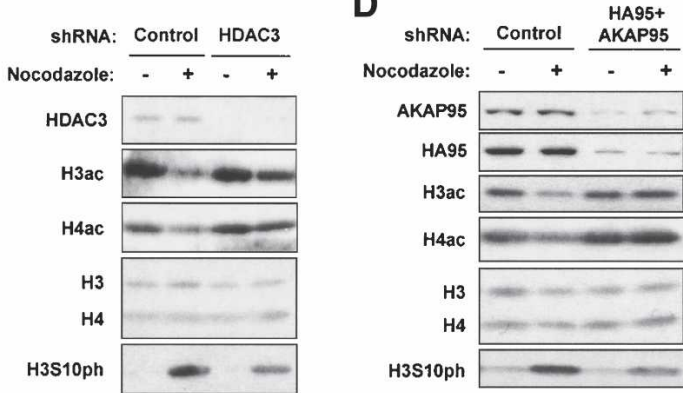

E

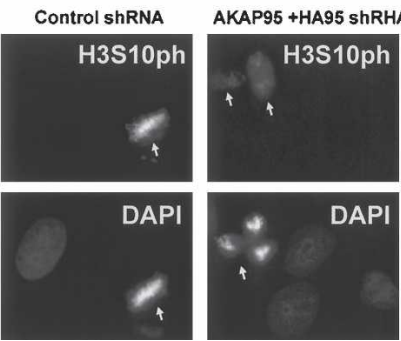

F

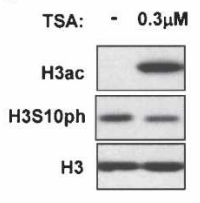

Figure 6. HDAC3 and AKAP95/HA95 are required for the $\mathrm{H} 3$ and H4 global deacetylation and for maximal phosphorylation of $\mathrm{H} 3 \mathrm{~S} 10 .(A) \mathrm{H} 3$ and $\mathrm{H} 4$ are globally hypoacetylated during mitosis. Total histones were acid extracted from 293T cells synchronized by nocodazole (or not) and separated by SDS-PAGE. Total $\mathrm{H} 3$ and $\mathrm{H} 4$, acetylated $\mathrm{H} 3$ and $\mathrm{H} 4$ (H3ac and $\mathrm{H} 4 \mathrm{ac})$, and phosphorylated H3S10 (H3S10ph) were detected by Western blot. (B) Mass spectrometric analysis of relative abundance of selected modification on $\mathrm{H} 3$ tails from asynchronously or nocodazole-synchronized HeLa cells. Each bar presents the percentage of $\mathrm{H} 3$ peptide with the indicated modifications in total H3 tail peptides population as determined by mass spectrometry (Supplementary Fig. 6A,B). (C) Histone acetylation decreases in mitosis in an HDAC3-dependent manner. Vectors containing HDAC3 or a nonspecific control shRNA were transfected into 293T cells. After the second transfection, the cells were treated with nocodazole and collected for histone extraction and Western blot. $(D)$ Knockdown of AKAP95/HA95 abolished the hypoacetylation of $\mathrm{H} 3$ and $\mathrm{H} 4$ during mitosis. The experiments are similar to $C$ except using AKAP95 and HA95 shRNA. $(E)$ DAPI and H3 P-S10 staining of representative control and AKAP95/HA95 double-knockdown HeLa cells, showing reduced $\mathrm{H} 3 \mathrm{~S} 10$ phosphorylation (H3S10ph) in cells depleted of AKAP95 and HA95 shRNA. Arrows point to nuclei of mitotic cells. The experiments were repeated at least three times with similar results. $(F)$ MCF7 cells treated with TSA as in Figure 5A were acid-extracted followed by Western blot with indicated antibodies. 
tibodies to immunoprecipitate the hyperacetylated histones; hypoacetylated histones remained in the supernatant (Fig. 7A). H3S10 phosphorylation was detected in the hypoacetylated H3 fraction (supernatant), but not in the hyperacetylated $\mathrm{H} 3$ fraction (immunoprecipitate) (Fig. 7A).

We also tested this hypothesis by quantitative mass spectrometry (Fig. 7B). We reasoned that if H3S10 phosphorylation is affected by a given modification, that modification should be disproportionately represented in the H3S10-phosphorylated tails (cf. the $\mathrm{H} 3$ tails as a whole). Indeed, acetylation of H3 at K9 or K14 was underrepresented by $\sim 10$-fold in H3S10-phosphorylated tails $(0.22 \%$ as compared with $2.6 \%$ in the total $\mathrm{H} 3$ pool). In contrast, we observed a similar level of H3K9Me in total H3 tail peptides $(22.6 \%)$ as in H3S10-phosphorylated peptides $(24.8 \%)$, suggesting that H3S10 phosphorylation is not affected by methylation of K9. Moreover, we could not detect any S10 phosphorylated, doubly acetylated $\mathrm{H} 3$ tail peptide with current MS detection limits (Supplementary Fig. 8c; the calculated mass is $561.2708 \mathrm{~m} / \mathrm{z}$ ), although it is possible that the double acetyl/phospho-peptide exists at extremely low levels that may be detected with higher sensitivity immunoassay methods (Kruhlak et al. 2001). These data, while correlative, are consistent with the conclusion that acety-
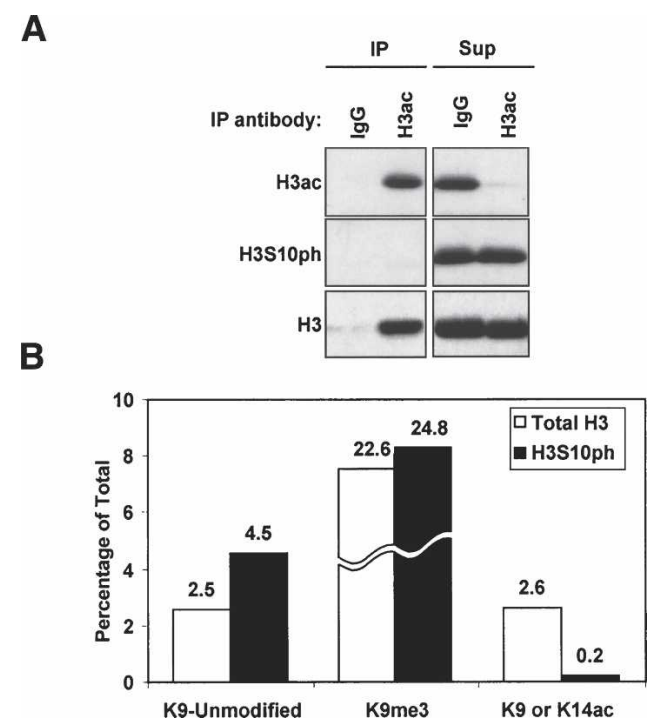

Figure 7. Phosphorylation of H3S10 occurs mainly on hypoacetylaed $\mathrm{H} 3$ tails. (A) $293 \mathrm{~T}$ cells were synchronized with nocodazole for $6 \mathrm{~h}$ to produce $\sim 40 \% \mathrm{G} 2 / \mathrm{M}$ cells. The cells were acid-extracted, and $10 \mu \mathrm{g}$ of extract was incubated with antiH3ac antibody. The supernatant (Sup) and immunoprecipitate (IP) fractions were analyzed for phosphorylation and acetylation levels by Western blot. $(B)$ Relative abundance of total unmodified $\mathrm{H} 3 \mathrm{~K} 9$, trimethylated $\mathrm{H} 3 \mathrm{~K} 9$ (H3K9me3), as well as acetylated H3K9 or H3K14 (H3K9ac or K3K14ac) peptides (open bars), with the percentage of each modified peptide in combination with H3S10 phosphorylation in the phosphorylated peptide population (black bars) isolated from nocodazole-synchronized mitotic HeLa cells as determined by mass spectrometry (Supplementary Fig. 8c). lation of $\mathrm{H} 3$ tails interferes with phosphorylation of the H3 tails, and, thus, hypoacetylation of H3 tails appears to be a prerequisite for mitotic H3S10 phosphorylation.

\section{The H3S10 kinase Aurora B is present in HDAC3 complexes during mitosis}

Thus far we have demonstrated that AKAP95/HA95HDAC3-dependent histone deacetylation correlates with the mitotic phosphorylation of H3S10. We hypothesized that the mechanism underlying this phenomenon involved Aurora B, the kinase that phosphorylates H3S10 during mitosis (Crosio et al. 2002; Meraldi et al. 2004). Indeed, we noted that Aurora B is associated with the HDAC3 complex during mitosis (Fig. 2B), and that after gel filtration of purified HDAC3 complexes, Aurora $B$ is present in the high-molecular-weight fractions that also contain AKAP95/HA95 and SMRT (Fig. 2E). Thus, Aurora B is a present in high-molecular-weight HDAC3 complexes.

\section{Hypoacetylated $\mathrm{H} 3$ is the preferred substrate for Aurora B kinase}

Consistent with a previous report (Shindo et al. 1998), Aurora B level is increased in cells arrested in mitosis (Supplementary Fig. 9). However, depletion of AKAP95/ HA95 or HDAC3 had little effect on Aurora B expression (Supplementary Fig. 9). We therefore hypothesized that the HDAC3-dependence of H3S10 phosphorylation was due to preferential phosphorylation of hypoacetylated H3 tails by Aurora B. This hypothesis was tested using an in vitro kinase assay to compare the ability of purified recombinant Aurora B to phosphorylate H3S10 in hyperacetylated versus hypoacetylated histone substrates. We first confirmed that H3S10 phosphorylation level was low and similar in the preparations of hypoacetylated and hyperacetylated histones (Supplementary Fig. 10). Consistent with our hypothesis, Aurora B more efficiently phosphorylates the hypoacetylated histone substrate, although its autophosphorylation was the same under both conditions (Fig. 8A).

We also examined whether the presence of the HDAC3/SMRT complex would facilitate S10 phosphorylation by native Aurora B complex purified from 293 T cells. The result indicated that incubation of the purified HDAC3/SMRT complex with purified endogenous Aurora B kinase complex dramatically increased the phosphorylation of H3S10 in an in vitro kinase assay (Fig. 8B). This result was not an artifact of the Western detection of H3S10 phosphorylation interfered by acetylation of $\mathrm{H} 3$, because in vitro deacetylation of the hyperacetylated histones using recombinant HDAC3/SMRT complex after the kinase assay did not increase the phosphorylation signal (Supplementary Fig. 11). Taken together, these data suggest that Aurora B kinase preferentially phosphorylates hypoacetylated H3. Based on these observations, we reason that hypoacetylated $\mathrm{H} 3$ is the preferred substrate for Aurora B kinase during mitosis, 
A

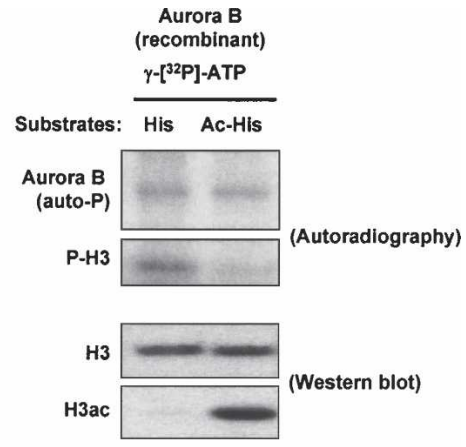

B

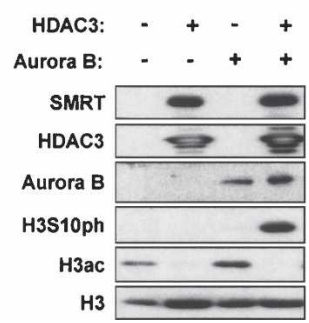

Figure 8. The H3S10 kinase Aurora B preferentially phosphorylates hypoacetylated H3. (A) Acid extracts from HeLa cells treated with sodium butyrate (Ac-His) or not (His) were used as the substrates for in vitro kinase assays with purified recombinant Aurora B using radiolabeled $\left[\gamma^{-{ }^{32}} \mathrm{P}\right] \mathrm{ATP}$ as described in Materials and Methods. H3S10 phosphorylation was detected by autoradiography. Autophosphorylation of Aurora B served as an internal control. H3 was Coomassie stained as a loading control. (B) Addition of HDAC3 complex increased phosphorylation of $\mathrm{H} 3 \mathrm{~S} 10$ by Aurora B complex. Affinity-purified endogenous Aurora B complex from 293T cells was incubated with hyperacetylated histones with or without addition of purified HDAC3/SMRT complex, followed by Western blot with indicated antibodies.

which explains why phosphorylation of $\mathrm{H} 3 \mathrm{~S} 10$ decreased in HDAC3 and AKAP95/HA95 complex-depleted mitotic cells.

\section{The AKAP95/HA95-HDAC3-Aurora B pathway is required for HP1 $\beta$ dissociation during mitosis}

The physiological function of mitotic H3S10 phosphorylation has been recently clarified by the recent finding that Aurora B phosphorylation of H3S10 results in the dissociation of HP1 proteins, notably HP $1 \beta$, despite persistent H3K9 trimethylation (Fischle et al. 2005; Hirota et al. 2005). We hypothesized that the AKAP95/HA95HDAC3-Aurora B pathway we have uncovered is upstream of this "meth-phos switch." Indeed, the overall decrease in H3S10 phosphorylation after knockdown of either HDAC3 or AKAP95/HA95 also occurs on H3 tails in which $\mathrm{H} 3 \mathrm{~K} 9$ is trimethylated, although the overall trimethylation of $\mathrm{H} 3 \mathrm{~K} 9$ was unchanged in HDAC3 or AKAP95/HA95 knockdown cells (Fig. 9A). Knockdown of HDAC1, which did not change acetylation levels of histones from mitotic-arrested cells, also did not reduce this double modification (Supplementary Fig. 3b).
If the AKAP95/HA95-HDAC3-Aurora B pathway is, indeed, a prerequisite for normal mitotic H3S10 phosphorylation leading to HP $1 \beta$ dissociation, then knockdown of the individual components of this pathway should result in retention of HP1 $\beta$ on mitotic chromatin. To test this hypothesis, HeLa cells were transfected with shHDAC3 or shAKAP95/shHA95 constructs, then stained with anti-HP1 $\beta$ after extraction of the soluble proteins to reduce the interference from soluble nonchromatin-bound proteins. As expected, in cells treated with control shRNA, HP1 $\beta$ was not extracted from interphase cells, but was completely extracted from mitotic cells (Fig. 9B, arrow). In contrast, HP1 $\beta$ was retained by mitotic chromatin in cells depleted of HDAC3 or AKAP95/HA95 (Fig. 9B). This was very similar to the effect of pharmacological inhibition of Aurora B using hesperadin, the hallmark of the "meth-phos switch" (Fischle et al. 2005; Hirota et al. 2005), which we also observed (Fig. 9C). These results demonstrate that normal HP1 dissociation from mitotic chromosomes requires the HDAC3-AKAP95/HA95-Aurora B pathway, acting upstream of the H3S10-phosphorylation-dependent displacement of HP1 from heterochromatin. They further predict that HDAC inhibitors acting on this pathway to induce mitotic arrest should cause HP1 $\beta$ retention. Indeed, the dissociation of HP1 $\beta$ from mitotic
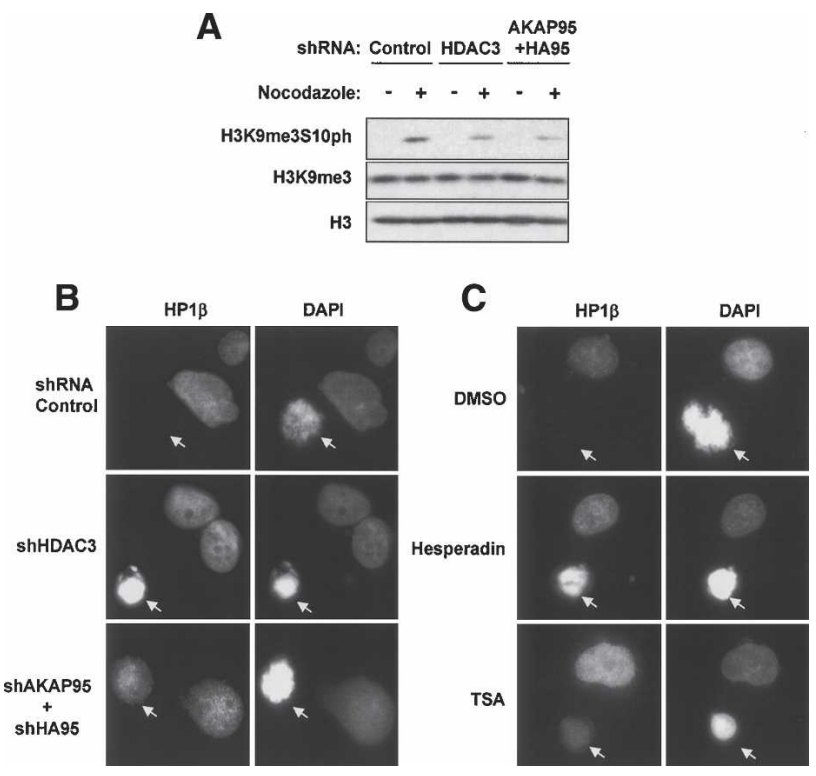

Figure 9. The AKAP95/HA95-HDAC3-Aurora B pathway is required for dissociation of HP1 from mitotic chromosomes. (A) Knockdown of HDAC3 as well as double knockdown of AKAP95 and HA95 decreases double modification of H3K9 trimethylation and S10 phosphorylation (H3K9Me3S10ph). (B) Immunofluorescence staining for anti-HP1 $\beta$ in HeLa cells transfected with control shRNA, AKAP95 and HA95 shRNA, or HDAC3 shRNA constructs. $(C)$ Immunofluorescence staining for anti-HP1 $\beta$ in HeLa cells treated with DMSO (control), Hesperadin, or TSA. Arrows indicate the mitotic cells with condensed chromosome stained by DAPI. The experiments were repeated twice with similar results. 
Li et al.

heterochromatin was prevented by treatment with TSA (Fig. 9C).

\section{Discussion}

The classic role of HDAC3 has been that of a transcriptional repressor of gene expression, as part of a complex tethered to sequence-specific transcription factors. Here we have reported the unexpected finding that HDAC3 has a critical, transcription-independent function in mitosis. In interphase cells, AKAP95/HA95 binds to the nuclear matrix (Collas et al. 1999; Martins et al. 2000; Akileswaran et al. 2001) and is less associated with HDAC3. HP1 proteins are recruited to methylated H3K9 in heterochromatin. When cells enter into mitosis, AKAP95/HA95 may target the HDAC3 complex to deacetylate $\mathrm{H} 3$, in a reaction that is blocked by HDAC inhibitors, and thereby provides a hypoacetylated $\mathrm{H} 3$ tail as substrate for Aurora B to phosphorylate on S10. Phosphorylation of S10 by Aurora B then dissociates HP1 proteins from methylated $\mathrm{H} 3 \mathrm{~K} 9$ residues on mitotic heterochromatin, which has been referred to as the "meth-phos switch" (Fischle et al. 2005; Hirota et al. 2005). These interdependent changes in histone modification and protein association are required for normal progression through mitosis, perhaps by facilitating chromosome condensation, or by serving as the indicator for the mitotic checkpoint to control proper cell division (Fig. 10).

While the transcriptional effect of HDAC inhibitors on specific genes, such as p21 and other cell cycle-regulated genes, has been reported to contribute to their antitumor actions, especially in G1-phase arrest (Archer et al. 1998; Sambucetti et al. 1999; Xiao et al. 1999; Richon et al. 2000; Johnstone 2002), their direct effects on histone acetylation levels may be equally important for the anti-tumor activity because of the important functions of histones in different cellular processes, including mitosis (Johnstone and Licht 2003). It is increasingly clear that HDAC inhibition induces G2/M arrest in many human cell lines and causes mitotic defects in different cancer cell lines (Qiu et al. 2000; Taddei et al. 2001; Bali et al. 2005; Dowling et al. 2005; Nome et al. 2005; Wong et al. 2005). We have confirmed this and, furthermore, find that this effect of HDAC inhibition is independent of ongoing gene transcription, suggesting direct effects of histone hyperacetylation on mitosis. Our results indicate that the hyperacetylation of histones induced by HDAC inhibitors directly interfere with mitotic progression.

Global histone acetylation is reduced during mitosis (Marian and Wintersberger 1982; Jeppesen et al. 1992; Kruhlak et al. 2001; Chen et al. 2005; Li et al. 2005; Valls et al. 2005; Nishiyama et al. 2006). Our studies reveal that HDAC3 and its partner proteins AKAP95 and HA95 are required for global histone deacetylation during mitosis. Of note, the most dramatic change in acetylation that occurs during mitosis is hypoacetylation of Lys 5 of H4 (Kruhlak et al. 2001), which matches the substrate specificity of HDAC3 (Hartman et al. 2005). Moreover,

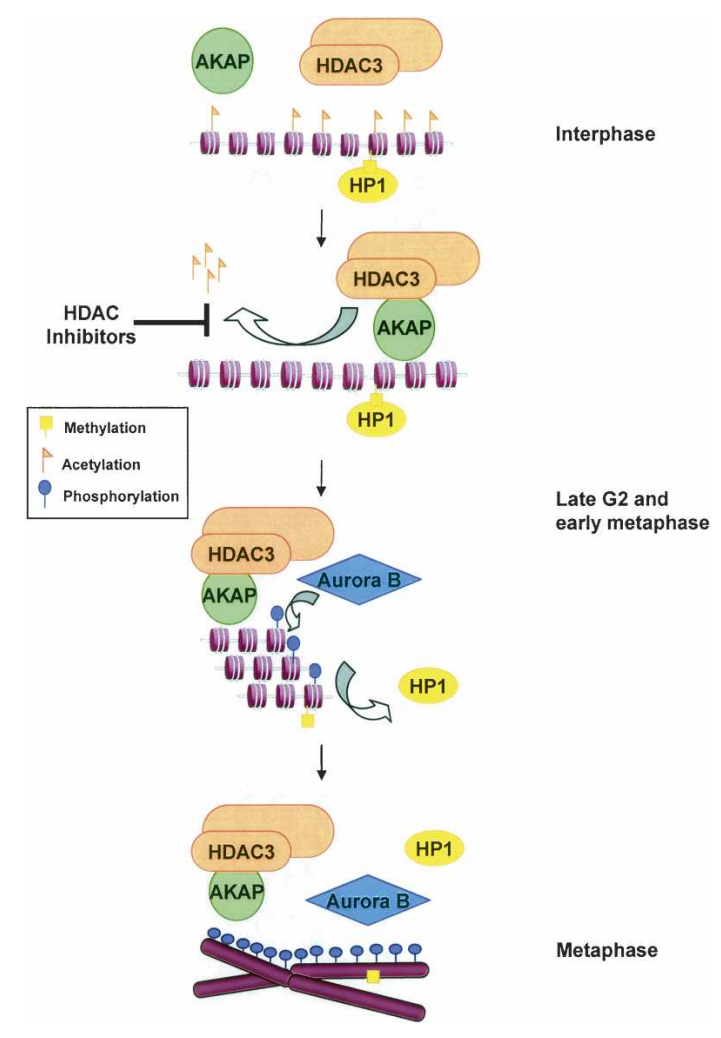

Figure 10. The HDAC3-AKAP95/HA95-Aurora B pathway regulating mitosis. In interphase cells, AKAP95/HA95 binds to the nuclear matrix (Mikhailov et al. 2004). HP1 proteins are recruited to the heterochromatin by interaction with methylated H3K9. When cells enter into mitosis, AKAP95/HA95 recruits HDAC3 along with Aurora B. HDAC3-mediated histone deacetylation enhances the H3S10 kinase activity of Aurora B. This step is blocked by HDAC inhibitors. Aurora B-catalyzed phosphorylation of H3S10 dissociates HP1 from mitotic chromosomes via the "meth-phos switch" (Fischle et al. 2005; Hirota et al. 2005). This pathway is required for normal progression through mitosis.

our results clearly show that HDAC3 is required for normal mitotic progression. This is consistent with a recent study in which knockdown of HDAC3, but not HDAC1 or HDAC2, increased cells in G2/M phase in human colon cancer cells (Wilson et al. 2006). Furthermore, knockdown of HDAC3 or AKAP95/HA95 also mimicked the effects of nonselective HDAC inhibition on phosphorylation of $\mathrm{H} 3 \mathrm{~S} 10$ and retention of $\mathrm{HP} 1 \beta$ proteins on mitotic chromosomes. Inhibition of HDAC3 is therefore likely to be the mechanism by which HDAC inhibitors induce the G2/M block in the cell cycle. The transcription independence of this effect, while unexpected, is completely consistent with a direct mitotic function of HDAC3 in the context of the novel pathway that we report here.

Specific patterns of histone modification at gene promoters regulate transcription via a "histone code" (Jenuwein and Allis 2001). Notably, the transient phosphorylation of H3S10 has been reported in the promoter region of many mammalian immediate-early genes, which are 
rapidly induced in response to extracellular stimuli including UV radiation, growth factors, and cytokines (Bode and Dong 2005). On these promoters, the phosphorylation of $\mathrm{H} 3 \mathrm{~S} 10$ precedes the H3K14 acetylation, resulting in multiple modifications of $\mathrm{H} 3$ that facilitate gene activation (Cheung et al. 2000a; Lo et al. 2000, 2001). On the contrary, we found that the phosphorylation of $\mathrm{H} 3 \mathrm{~S} 10$ by Aurora B during mitosis requires the previous deacetylation of histones by HDAC3. Thus, in contrast to the phosphorylation of H3S10 by other kinases that prefer preacetylated histone tails, the mitotic phosphorylation of H3S10 by Aurora B kinase is linked to the deacetylation of $\mathrm{H} 3$, specifically by HDAC3. This characteristic of Aurora B may be specific to metazoans because IPL1, the yeast homolog of Aurora kinase, phosphorylated both monoacetylated and unacetylated $\mathrm{H} 3$ (Rea et al. 2000). In addition to H3S10, Aurora B also phosphorylates H3S28 and other proteins including histone $\mathrm{H} 3$ variant centromere protein A (CENP-A) (Goto et al. 1999, 2002; Zeitlin et al. 2001; Kunitoku et al. 2003). In the human cell systems we have studied, Aurora B also seems to prefer hypoacetylated H3 and CENP-A H3 as substrate for phosphorylation of H3S28 and CENP-A Ser7, respectively (Y. Li and M.A. Lazar, unpubl.). The global hypoacetylation of $\mathrm{H} 3$ tail lysines in mitotic cells and their proximity to the major sites of phosphorylation by Aurora B kinase suggest that deacetylation of histone substrates may be a general preference for Aurora B function. The relative importance of specific hypoacetylated lysines for phosphorylation of specific serine residues remains to be elucidated.

The specificity of Aurora B toward hypoacetylated histone substrate suggests a mechanistic link between HDAC3-dependent histone deacetylation and a transcription-independent mechanism of mitotic arrest. H3S10 phosphorylation during mitosis is characteristic of many organisms (Wei et al. 1999; Crosio et al. 2002), and is dependent on Aurora B kinase, which plays a central role throughout different stage of mitosis, including chromosome condensation, alignment, and segregation, spindle assembly, and cytokinesis (Schumacher et al. 1998; Giet and Glover 2001; Hauf et al. 2003; Gimenez-Abian et al. 2004). The recent finding that Auroradependent phosphorylation of H3S10 dissociates HP1 from mitotic heterochromatin provides molecular insight into the function of Aurora B (Fischle et al. 2005; Hirota et al. 2005). Our findings implicate AKAP95/HA95 and HDAC3 as upstream regulators of this "meth-phos switch" (Fischle et al. 2003), and provide a molecular mechanism to explain the anti-cancer effects of HDAC inhibitors. Aurora B kinase itself is overexpressed in a large number of cancers (Takahashi et al. 2000; Sorrentino et al. 2005). Our finding that Aurora B is present in HDAC3 complexes and that its kinase activity is dramatically greater when the $\mathrm{H} 3$ tail is hypoacetylated suggests that the interdependence of Aurora B and HDAC3 may be a novel and specific target for cancer therapies that would overcome the toxicity of nonspecific HDAC inhibitors.

\section{Materials and methods}

\section{Plasmids and reagents}

Full-length AKAP95 and HA95 were obtained from HeLa cells by RT-PCR and cloned into pcDNA3.1A vector (Invitrogen). HA-epitope tags were added to the $\mathrm{N}$ terminus of HA95 and the $\mathrm{C}$ terminus of AKAP95. The pTRE-HDAC3-Flag expression vector was constructed by inserting HDAC3-Flag (Guenther et al. 2001) into the pTRE vector (BD Clontech). The SMRT DAD domain or SMRT 1-763, fused to the Gal4 DNA-binding domain, were described previously (Yu et al. 2003). Anti-HA95 and AKAP95 antibodies were raised against KLH-conjugated peptides HA95 (amino acids 65-85) and AKAP95 (amino acids 672688) and affinity-purified. Anti-GPS2 antibody was raised against the peptide from 307 to 327 (Covance). N-CoR and TBL1 antibodies were described previously (Huang et al. 2000; Guenther et al. 2001). Other antibodies were purchased as follows: $\mathrm{H} 4, \mathrm{H} 3 \mathrm{ac}, \mathrm{H} 4 \mathrm{ac}, \mathrm{H} 3 \mathrm{~S} 10 \mathrm{ph}$, and H3K9me3S10ph from Upstate Biotechnology; H3, H3K9acS10ph, anti-HDAC3 (rabbit), and anti-Aurora B from Abcam; anti-HDAC3 (mouse), anti-SMRT, and anti-Ran from BD PharMingen; mouse anti-HDAC3 for immunoprecipitation from Upstate Biotechnology (clone 3G6); anti-SMRT/N-CoR from Affinity Bioreagents; anti-GAPDH from Santa Cruz Biotechnology; anti-Tcp1 $\beta$ from Stressgen Biotechnologies; anti-Flag from Sigma; and anti-HA tag from Roche Applied Science. TSA, sodium butyrate, VPA, nocodazole, paclitaxel, and aphidicolin were purchased from Sigma.

\section{Cell line establishment and culture conditions}

293T, HeLa, and MCF7 cells were kept in DMEM with 10\% FBS. The 293T tet-off cell line (BD Clontech) was transfected with pTRE-HDAC3-Flag or pTRE empty vector and selected under $50 \mu \mathrm{g} / \mathrm{mL}$ hygromycin in DMEM with $5 \%$ FBS. Positive clones were confirmed by Western blot. The HDAC3-Flag expression level of the selected clone was about five times higher than endogenous HDAC3 (data not shown). The HDAC3 stable cell lines were kept in DMEM with either 5\% tet-approved FBS (BD Clontech) to express HDAC3-Flag or $5 \%$ FBS with $2 \mu \mathrm{g} / \mathrm{mL}$ Doxycycline (Sigma) to turn off HDAC3 expression.

\section{Affinity purification and gel filtration}

Flag-HDAC3 stable cell pellets were resuspended in BC100 buffer $(20 \mathrm{mM}$ HEPES, $100 \mathrm{mM} \mathrm{KCl}, 0.2 \%$ NP-40, $0.2 \mathrm{mM}$ EDTA, $10 \%$ glycerol, $0.2 \mathrm{mM}$ DTT, protease inhibitor cocktail [Roche]) followed by brief sonication to lyse the cells. Wholecell lysates were incubated with anti-Flag M2 agarose (Sigma) in BC100 buffer overnight at $4^{\circ} \mathrm{C}$. After extensive washing with $\mathrm{BC} 100$ and BC300 (20 mM HEPES, $300 \mathrm{mM} \mathrm{KCl}, 0.2 \%$ NP-40, $0.2 \mathrm{mM}$ EDTA, $10 \%$ glycerol, $0.2 \mathrm{mM}$ DTT), associated complexes were eluted by $0.5 \mathrm{mg} / \mathrm{mL}$ Flag peptide (Sigma) or 0.2 $\mathrm{mg} / \mathrm{mL} 3 x$ Flag peptide (Sigma) in BC100 buffer or BC100 without NP-40 (for gel filtration). For gel filtration, eluents were concentrated to $0.15 \mathrm{~mL}$ on an Ultrafree cellulose concentration device (Millipore). The samples were loaded on a Superose 6 10/30 gel filtration column (Amersham Bioscience) in BC150 (150 mM KCl) without NP-40. Eluents were collected at $0.5 \mathrm{~mL}$ per fraction. Fractions from the Superose 6 column were subjected to immunoblot analysis.

\section{Protein identification}

Protein identification by mass spectrometry was performed as described (Jung et al. 2005). 


\section{Immunoprecipitation}

Cells were lysed with BC100 for 10 min on ice followed by brief sonication. After centrifugation, the supernatants were precleared with protein A agarose, and then allowed to bind either anti-HDAC3 or anti-HA95 and anti-AKAP95 overnight at $4^{\circ} \mathrm{C}$. Protein A agarose beads were added and incubated for another 2 $\mathrm{h}$. The beads were washed five times in BC100 and once in BC300 and subjected to immunoblot analysis. For in vitro binding assays, Flag-HDAC3 and Gal-SMRT(1-763) were in vitro translated with the T7 TNT Quick Coupled Transcription/ Translation System (Promega) and incubated with anti-Flag M2 agarose (Sigma) in $\mathrm{BC} 100$ buffer overnight at $4^{\circ} \mathrm{C}$. HDAC3coupled beads were collected and incubated with in vitro translated, ${ }^{35}$ S-labeled HA95 or AKAP95, which were precleared with anti-Flag M2 agarose in BC100 buffer. After extensive washing, bound proteins were subjected to autoradiography and immunoblot analysis.

\section{shRNA transfection}

Vectors expressing shRNA under the control of the human $\mathrm{H} 1$ promoter were constructed by inserting pairs of annealed DNA oligonucleotides into the pSuper vector (Oligoengine) between $\mathrm{BglII}$ and HindIII restriction sites or pSilenser vector (for HDAC1 and control for HDAC1; Ambion). The target sequences were as follows: nontargeted control: 5'-AGACACACGCACTCGTC TC-3'; HA95-1: 5'-CCCAGCCATCTTGACAGCAA-3'; AKAP95-1: 5'-GCCAGGAGCACTTCTTCAA-3'; HDAC1, HDAC3 control for HDAC1: see Ishizuka and Lazar (2003).

$293 \mathrm{~T}$ or HeLa cells were transfected with shRNAs using Lipofectamine 2000 (Invitrogen Gibco) according to the manufacturer's instructions. Cells were divided $24 \mathrm{~h}$ after transfection, followed by a second transfection $24 \mathrm{~h}$ later with the same shRNA constructs. Cells were split after an additional $24 \mathrm{~h}$ incubation, and specific drugs were added at the indicated concentration and collected at various time points.

\section{In vitro kinase assay and HDAC assay}

One microgram of sodium-butyrate-treated (hyperacetylated) or untreated histones from HeLa cells (Upstate Biotechnology) was incubated with $2.5 \mathrm{U}$ of active Aurora B (Upstate Biotechnology) in $\mathrm{TAB}$ kinase buffer (Upstate Biotechnology) for $10 \mathrm{~min}$ at $30^{\circ} \mathrm{C}$. The reaction included either $\mathrm{Mg}^{2+}$ ATP cocktail (Upstate Biotechnology) or $0.2 \mu \mathrm{Ci}$ of $\left[\gamma^{-32} \mathrm{P}\right] \mathrm{ATP}$ plus $\mathrm{Mg}^{2+}$ ATP cocktail. The reactions were stopped by addition of $2 \times$ SDS loading buffer and boiling for $5 \mathrm{~min}$ at $95^{\circ} \mathrm{C}$. Phosphorylation of histones was detected by Western blot or autoradiography. After kinase assay, the samples were diluted with HDAC buffer together with beads alone or anti-Flag agarose-immobilized HDAC3 and SMRT DAD, which are overexpressed in 293T cells. HDAC assay was performed as described previously (Yu et al. 2003). In vitro kinase assays were also performed using affinity-purified Aurora B complex from 293T cells. Five micrograms of hyperacetylated histones were incubated with immobilized HDAC3SMRT DAD complex or beads alone at $37^{\circ} \mathrm{C}$ in TAB kinase buffer. After $20 \mathrm{~min}$ of incubation, affinity-purified Aurora B complex from $293 \mathrm{~T}$ cells was added to the reactions with $\mathrm{Mg}^{2+}$ ATP cocktail. The reactions were incubated for $15 \mathrm{~min}$ more and stopped by addition of SDS loading buffer and boiling.

\section{FACS}

Cells were trypsinized, washed with PBS, and fixed with icecold $70 \%$ ethanol overnight at $4^{\circ} \mathrm{C}$. Nucleus DNA was stained using a solution with $50 \mu \mathrm{g} / \mathrm{mL}$ propidium iodide (Sigma) and 1 $\mathrm{mg} / \mathrm{mL}$ RNase A in PBS (Jin et al. 2002). The cells were analyzed on FACScalibur (BD Biosciences) using CellQuest and ModFit data analysis software.

\section{Immunofluorescence}

For colocalization staining of AKAP95 and HDAC3, HeLa cells cultured on Lab-TekII Chamber slides were washed three times in PBS, fixed for $15 \mathrm{~min}$ in $3 \%$ paraformaldehyde (PFA) at room temperature, washed, and fixed with cold methanol for $5 \mathrm{~min}$. After two additional washes, cells were incubated with blocking buffer (5\% donkey serum in PBS) for $1 \mathrm{~h}$ at room temperature. Primary antibodies were diluted in blocking buffer and incubated with cells at $4^{\circ} \mathrm{C}$ overnight. After washing with PBS three times, cells were incubated with secondary antibodies conjugated with either Alexa 594 or Alexa 488 (Molecular Probes) for $1 \mathrm{~h}$ at room temperature. Then DNA was stained with $0.1 \mathrm{mg} /$ $\mathrm{mL}$ 4',6-diamidino-2-phenylindole (DAPI; Sigma) for $15 \mathrm{~min}$ at room temperature. After washing, slides were mounted with Prolong Gold anti-fade reagent. Slides were viewed with a Zeiss LSM-510 META confocal microscope, using LSM 510 version 3.2 software to acquire images.

Alternatively, cells were cultured on chamber slides and incubated with $0.5 \%$ Triton X-100 in PBS for 5 min at room temperature to extract non-chromatin-bound proteins. After fixing and staining with indicated antibodies or DAPI, additional imaging was performed with a 100× PlanNeofluor objective mounted on a Nikon TE-200 microscope equipped with epifluorescence optics. With the latter, images were captured with a Hammamatsu CCD camera that was controlled with IP LabSpectrum version 2.0.1 (Scanalytics, Inc.).

\section{Mass spectrometry (MS)}

The mass spectrometry data shown in Supplementary Figures 6 and 8 are summarized in Figures 6B and 7B. H3 from asynchronously grown and mitotically arrested HeLa cells were first chemically derivatized with propionylation reagent (Aldrich) as previously described (Syka et al. 2004). H3 was dried to near dryness and redissolved in $25 \mu \mathrm{L}$ of deionized water, diluted with $50 \mu \mathrm{L}$ of $100 \mathrm{mM}$ ammonium bicarbonate buffer solution $(\mathrm{pH} 8)$, and digested with trypsin (Promega) at a substrate:enzyme ratio of $20: 1$ for $5 \mathrm{~h}$ at $37^{\circ} \mathrm{C}$. All reactions were quenched by the addition of concentrated acetic acid and freezing. Propionylated histone digest mixtures were loaded onto capillary precolumns packed with $5 \mathrm{~cm}$ of irregular C18 resin, washed with $0.1 \%$ acetic acid, and connected to analytical columns packed with $8 \mathrm{~cm}$ of regular $\mathrm{C} 18$ resin $(5 \mu \mathrm{m}$; YMC, Inc.) constructed with integrated electrospray emitters as previously published (Martin et al. 2000). All samples were analyzed by nanoflow HPLC-microelectrospray ionization on a Finnigan linear quadrupole ion trap-Fourier Transform Ion Cyclotron Resonance (LTQ-FT-ICR) mass spectrometer (Thermo Electron) as previously described (Hake et al. 2006).

\section{Acknowledgments}

We thank Dr. S. Berger, G. Blobel, M. Brown, D. Chakravarti, P. Kushner, and J. Yu for helpful discussions and T. Alenghat for critically reading the manuscript. We gratefully acknowledge $S$. Hake, W. Fischel, and C.D. Allis for providing the histone samples for mass spectrometry analysis and W. Fischle for helping discussions. We also thank Dr. X. Zhao in the Biomedical Imaging Core of the Penn Diabetes and Endocrinology Research 
Center (DK19525) for help with confocal microscopy, and the FACS core of the Abramson Cancer Center. This work was funded by the NIH grants Nuclear Receptor Signaling Atlas (NURSA) DK062434 (to M.A.L. and J.Q.) and CA-107956 (to G.D.K.); GM37537 (to D.F.H.), by the Office of Research and Development, Medical Research Service, Department of Veterans Affairs (to G.D.K.); and by the Ford Foundation (to B.A.G.).

\section{References}

Adams, R.R., Maiato, H., Earnshaw, W.C., and Carmena, M. 2001. Essential roles of Drosophila inner centromere protein (INCENP) and Aurora B in histone H3 phosphorylation, metaphase chromosome alignment, kinetochore disjunction, and chromosome segregation. J. Cell Biol. 153: 865-880.

Akileswaran, L., Taraska, J.W., Sayer, J.A., Gettemy, J.M., and Coghlan, V.M. 2001. A-kinase-anchoring protein AKAP95 is targeted to the nuclear matrix and associates with p68 RNA helicase. J. Biol. Chem. 276: 17448-17454.

Archer, S.Y., Meng, S., Shei, A., and Hodin, R.A. 1998. p21(WAF1) is required for butyrate-mediated growth inhibition of human colon cancer cells. Proc. Natl. Acad. Sci. 95: 6791-6796.

Bali, P., Pranpat, M., Bradner, J., Balasis, M., Fiskus, W., Guo, F., Rocha, K., Kumaraswamy, S., Boyapalle, S., Atadja, P., et al. 2005. Inhibition of histone deacetylase 6 acetylates and disrupts the chaperone function of heat shock protein 90: A novel basis for antileukemia activity of histone deacetylase inhibitors. J. Biol. Chem. 280: 26729-26734.

Bode, A.M. and Dong, Z. 2005. Inducible covalent posttranslational modification of histone H3. Sci. STKE 2005: re4.

Chen, D., Dundr, M., Wang, C., Leung, A., Lamond, A., Misteli, T., and Huang, S. 2005. Condensed mitotic chromatin is accessible to transcription factors and chromatin structural proteins. J. Cell Biol. 168: 41-54.

Cheung, P., Tanner, K.G., Cheung, W.L., Sassone-Corsi, P., Denu, J.M., and Allis, C.D. 2000a. Synergistic coupling of histone $\mathrm{H} 3$ phosphorylation and acetylation in response to epidermal growth factor stimulation. Mol. Cell 5: 905-915.

Cheung, W.L., Briggs, S.D., and Allis, C.D. 2000b. Acetylation and chromosomal functions. Curr. Opin. Cell Biol. 12: 326333.

Cobb, J., Miyaike, M., Kikuchi, A., and Handel, M.A. 1999. Meiotic events at the centromeric heterochromatin: Histone $\mathrm{H} 3$ phosphorylation, topoisomerase II $\alpha$ localization and chromosome condensation. Chromosoma 108: 412-425.

Collas, P., Le Guellec, K., and Tasken, K. 1999. The A-kinaseanchoring protein AKAP95 is a multivalent protein with a key role in chromatin condensation at mitosis. J. Cell Biol. 147: 1167-1180.

Crosio, C., Fimia, G.M., Loury, R., Kimura, M., Okano, Y., Zhou, H., Sen, S., Allis, C.D., and Sassone-Corsi, P. 2002. Mitotic phosphorylation of histone H3: Spatio-temporal regulation by mammalian Aurora kinases. Mol. Cell. Biol. 22: 874-885.

Della Ragione, F., Criniti, V., Della Pietra, V., Borriello, A., Oliva, A., Indaco, S., Yamamoto, T., and Zappia, V. 2001. Genes modulated by histone acetylation as new effectors of butyrate activity. FEBS Lett. 499: 199-204.

Dowling, M., Voong, K.R., Kim, M., Keutmann, M.K., Harris, E., and Kao, G.D. 2005. Mitotic spindle checkpoint inactivation by trichostatin a defines a mechanism for increasing cancer cell killing by microtubule-disrupting agents. Cancer Biol. Ther. 4: 197-206.

Eide, T., Carlson, C., Tasken, K.A., Hirano, T., Tasken, K., and
Collas, P. 2002. Distinct but overlapping domains of AKAP95 are implicated in chromosome condensation and condensin targeting. EMBO Rep. 3: 426-432.

Emiliani, S., Fischle, W., Van Lint, C., Al-Abed, Y., and Verdin, E. 1998. Characterization of a human RPD3 ortholog, HDAC3. Proc. Nat1. Acad. Sci. 95: 2795-2800.

Fischle, W., Wang, Y., and Allis, C.D. 2003. Binary switches and modification cassettes in histone biology and beyond. $\mathrm{Na}$ ture 425: 475-479.

Fischle, W., Tseng, B.S., Dormann, H.L., Ueberheide, B.M., Garcia, B.A., Shabanowitz, J., Hunt, D.F., Funabiki, H., and Allis, C.D. 2005. Regulation of HP1-chromatin binding by histone H3 methylation and phosphorylation. Nature 438: 1116-1122.

Giet, R. and Glover, D.M. 2001. Drosophila Aurora B kinase is required for histone $\mathrm{H} 3$ phosphorylation and condensin recruitment during chromosome condensation and to organize the central spindle during cytokinesis. J. Cell Biol. 152: 669682.

Gimenez-Abian, J.F., Sumara, I., Hirota, T., Hauf, S., Gerlich, D., de la Torre, C., Ellenberg, J., and Peters, J.M. 2004. Regulation of sister chromatid cohesion between chromosome arms. Curr. Biol. 14: 1187-1193.

Goto, H., Tomono, Y., Ajiro, K., Kosako, H., Fujita, M., Sakurai, M., Okawa, K., Iwamatsu, A., Okigaki, T., Takahashi, T., et al. 1999. Identification of a novel phosphorylation site on histone $\mathrm{H} 3$ coupled with mitotic chromosome condensation. J. Biol. Chem. 274: 25543-25549.

Goto, H., Yasui, Y., Nigg, E.A., and Inagaki, M. 2002. Aurora-B phosphorylates Histone $\mathrm{H} 3$ at serine 28 with regard to the mitotic chromosome condensation. Genes Cells 7: 11-17.

Grunstein, M. 1997. Histone acetylation in chromatin structure and transcription. Nature 389: 349-352.

Guenther, M.G., Lane, W.S., Fischle, W., Verdin, E., Lazar, M.A., and Shiekhattar, R. 2000. A core SMRT corepressor complex containing HDAC3 and TBL1, a WD40-repeat protein linked to deafness. Genes \& Dev. 14: 1048-1057.

Guenther, M.G., Barak, O., and Lazar, M.A. 2001. The SMRT and $\mathrm{N}-\mathrm{CoR}$ corepressors are activating cofactors for histone deacetylase 3. Mol. Cell. Biol. 21: 6091-6101.

Guenther, M.G., Yu, J., Kao, G.D., Yen, T.J., and Lazar, M.A. 2002. Assembly of the SMRT-histone deacetylase 3 repression complex requires the TCP-1 ring complex. Genes \& Dev. 16: 3130-3135.

Gurley, L.R., Walters, R.A., and Tobey, R.A. 1973. Histone phosphorylation in late interphase and mitosis. Biochem. Biophys. Res. Commun. 50: 744-750.

Hake, S.B., Garcia, B.A., Duncan, E.M., Kauer, M., Dellaire, G., Shabanowitz, J., Bazett-Jones, D.P., Allis, C.D., and Hunt, D.F. 2006. Expression patterns and post-translational modifications associated with mammalian histone $\mathrm{H} 3$ variants. $J$. Biol. Chem. 281: 559-568.

Hartman, H.B., Yu, J., Alenghat, T., Ishizuka, T., and Lazar, M.A. 2005. The histone-binding code of nuclear receptor corepressors matches the substrate specificity of histone deacetylase 3. EMBO Rep. 6: 445-451.

Hauf, S., Cole, R.W., LaTerra, S., Zimmer, C., Schnapp, G., Walter, R., Heckel, A., van Meel, J., Rieder, C.L., and Peters, J.M. 2003. The small molecule Hesperadin reveals a role for Aurora B in correcting kinetochore-microtubule attachment and in maintaining the spindle assembly checkpoint. J. Cell Biol. 161: 281-294.

Hendzel, M.J., Wei, Y., Mancini, M.A., Van Hooser, A., Ranalli, T., Brinkley, B.R., Bazett-Jones, D.P., and Allis, C.D. 1997. Mitosis-specific phosphorylation of histone $\mathrm{H} 3$ initiates primarily within pericentromeric heterochromatin during G2 
and spreads in an ordered fashion coincident with mitotic chromosome condensation. Chromosoma 106: 348-360.

Hirota, T., Lipp, J.J., Toh, B.H., and Peters, J.M. 2005. Histone H3 serine 10 phosphorylation by Aurora B causes HP1 dissociation from heterochromatin. Nature 438: 1176-1180.

Hsu, J.Y., Sun, Z.W., Li, X., Reuben, M., Tatchell, K., Bishop, D.K., Grushcow, J.M., Brame, C.J., Caldwell, J.A., Hunt, D.F., et al. 2000. Mitotic phosphorylation of histone H3 is governed by Ipl1/aurora kinase and Glc7/PP1 phosphatase in budding yeast and nematodes. Cell 102: 279-291.

Huang, E.Y., Zhang, J., Miska, E.A., Guenther, M.G., Kouzarides, T., and Lazar, M.A. 2000. Nuclear receptor corepressors partner with class II histone deacetylases in a Sin3-independent repression pathway. Genes \& Dev. 14: 45-54.

Ishizuka, T. and Lazar, M.A. 2003. The N-CoR/histone deacetylase 3 complex is required for repression by thyroid hormone receptor. Mol. Cell. Biol. 23: 5122-5131.

- 2005. The nuclear receptor corepressor deacetylase activating domain is essential for repression by thyroid hormone receptor. Mol. Endocrinol. 19: 1443-1451.

Jenuwein, T. and Allis, C.D. 2001. Translating the histone code. Science 293: 1074-1080.

Jeppesen, P., Mitchell, A., Turner, B., and Perry, P. 1992. Antibodies to defined histone epitopes reveal variations in chromatin conformation and underacetylation of centric heterochromatin in human metaphase chromosomes. Chromosoma 101: 322-332.

Jin, Z., Dicker, D.T., and El-Deiry, W.S. 2002. Enhanced sensitivity of G1 arrested human cancer cells suggests a novel therapeutic strategy using a combination of simvastatin and TRAIL. Cell Cycle 1: 82-89.

Johnstone, R.W. 2002. Histone-deacetylase inhibitors: Novel drugs for the treatment of cancer. Nat. Rev. Drug Discov. 1: 287-299.

Johnstone, R.W. and Licht, J.D. 2003. Histone deacetylase inhibitors in cancer therapy: Is transcription the primary target? Cancer Cell 4: 13-18.

Jung, S.Y., Malovannaya, A., Wei, J., O'Malley, B.W., and Qin, J. 2005. Proteomic analysis of steady-state nuclear hormone receptor coactivator complexes. Mol. Endocrinol. 19: 24512465.

Kim, H.K., Kong, M.Y., Jeong, M.J., Han, D.C., Choi, J.D., Kim, H.Y., Yoon, K.S., Kim, J.M., Son, K.H., and Kwon, B.M. 2005. Investigation of cell cycle arrest effects of actinomycin D at G1 phase using proteomic methods in B104-1-1 cells. Int. J. Biochem. Cell Biol. 37: 1921-1929.

Kruhlak, M.J., Hendzel, M.J., Fischle, W., Bertos, N.R., Hameed, S., Yang, X.J., Verdin, E., and Bazett-Jones, D.P. 2001. Regulation of global acetylation in mitosis through loss of histone acetyltransferases and deacetylases from chromatin. J. Biol. Chem. 276: 38307-38319.

Kunitoku, N., Sasayama, T., Marumoto, T., Zhang, D., Honda, S., Kobayashi, O., Hatakeyama, K., Ushio, Y., Saya, H., and Hirota, T. 2003. CENP-A phosphorylation by Aurora-A in prophase is required for enrichment of Aurora-B at inner centromeres and for kinetochore function. Dev. Cell 5: 853 864.

Li, J., Wang, J., Wang, J., Nawaz, Z., Liu, J.M., Qin, J., and Wong, J. 2000. Both corepressor proteins SMRT and N-CoR exist in large protein complexes containing HDAC3. EMBO J. 19: 4342-4350.

Li, Y., Butenko, Y., and Grafi, G. 2005. Histone deacetylation is required for progression through mitosis in tobacco cells. Plant T. 41: 346-352.

Lo, W.S., Trievel, R.C., Rojas, J.R., Duggan, L., Hsu, J.Y., Allis, C.D., Marmorstein, R., and Berger, S.L. 2000. Phosphoryla- tion of serine 10 in histone $\mathrm{H} 3$ is functionally linked in vitro and in vivo to Gen5-mediated acetylation at lysine 14. Mol. Cell 5: 917-926.

Lo, W.S., Duggan, L., Emre, N.C., Belotserkovskya, R., Lane, W.S., Shiekhattar, R., and Berger, S.L. 2001. Snf1-A histone kinase that works in concert with the histone acetyltransferase Gen5 to regulate transcription. Science 293: 11421146.

Marian, B. and Wintersberger, U. 1982. Modification of histones during the mitotic and meiotic cycle of yeast. FEBS Lett. 139: $72-76$.

Marks, P.A., Richon, V.M., Breslow, R., and Rifkind, R.A. 2001. Histone deacetylase inhibitors as new cancer drugs. Curr. Opin. Oncol. 13: 477-483.

Martin, S.E., Shabanowitz, J., Hunt, D.F., and Marto, J.A. 2000. Subfemtomole MS and MS/MS peptide sequence analysis using nano-HPLC micro-ESI fourier transform ion cyclotron resonance mass spectrometry. Anal. Chem. 72: 4266-4274.

Martins, S.B., Eide, T., Steen, R.L., Jahnsen, T., Skalhegg, B.S., and Collas, P. 2000. HA95 is a protein of the chromatin and nuclear matrix regulating nuclear envelope dynamics. J. Cell Sci. 113: 3703-3713.

Meraldi, P., Honda, R., and Nigg, E.A. 2004. Aurora kinases link chromosome segregation and cell division to cancer susceptibility. Curr. Opin. Genet. Dev. 14: 29-36.

Mikhailov, A., Shinohara, M., and Rieder, C.L. 2004. Topoisomerase II and histone deacetylase inhibitors delay the G2/M transition by triggering the p38 MAPK checkpoint pathway. I. Cell Biol. 166: 517-526.

Nishiyama, A., Dey, A., Miyazaki, J., and Ozato, K. 2006. Brd4 is required for recovery from antimicrotubule drug-induced mitotic arrest: Preservation of acetylated chromatin. Mol. Biol. Cell 17: 814-823.

Nome, R.V., Bratland, A., Harman, G., Fodstad, O., Andersson, Y., and Ree, A.H. 2005. Cell cycle checkpoint signaling involved in histone deacetylase inhibition and radiation-induced cell death. Mol. Cancer Ther. 4: 1231-1238.

Orstavik, S., Eide, T., Collas, P., Han, I.O., Tasken, K., Kieff, E., Jahnsen, T., and Skalhegg, B.S. 2000. Identification, cloning and characterization of a novel nuclear protein, HA95, homologous to A-kinase anchoring protein 95. Biol. Cell. 92: $27-37$.

Ozawa, Y., Towatari, M., Tsuzuki, S., Hayakawa, F., Maeda, T., Miyata, Y., Tanimoto, M., and Saito, H. 2001. Histone deacetylase 3 associates with and represses the transcription factor GATA-2. Blood 98: 2116-2123.

Paulson, J.R. and Taylor, S.S. 1982. Phosphorylation of histones 1 and 3 and nonhistone high mobility group 14 by an endogenous kinase in HeLa metaphase chromosomes. I. Biol. Chem. 257: 6064-6072.

Qiu, L., Burgess, A., Fairlie, D.P., Leonard, H., Parsons, P.G., and Gabrielli, B.G. 2000. Histone deacetylase inhibitors trigger a G2 checkpoint in normal cells that is defective in tumor cells. Mol. Biol. Cell 11: 2069-2083.

Rea, S., Eisenhaber, F., O'Carroll, D., Strahl, B.D., Sun, Z.W., Schmid, M., Opravil, S., Mechtler, K., Ponting, C.P., Allis, C.D., et al. 2000. Regulation of chromatin structure by sitespecific histone H3 methyltransferases. Nature 406: 593-599.

Richie, C.T. and Golden, A. 2005. Chromosome segregation: Aurora B gets Tousled. Curr. Biol. 15: R379-R382.

Richon, V.M., Sandhoff, T.W., Rifkind, R.A., and Marks, P.A. 2000. Histone deacetylase inhibitor selectively induces p21WAF1 expression and gene-associated histone acetylation. Proc. Natl. Acad. Sci. 97: 10014-10019.

Robbins, A.R., Jablonski, S.A., Yen, T.J., Yoda, K., Robey, R., Bates, S.E., and Sackett, D.L. 2005. Inhibitors of histone 
deacetylases alter kinetochore assembly by disrupting pericentromeric heterochromatin. Cell Cycle 4: 717-726.

Sambucetti, L.C., Fischer, D.D., Zabludoff, S., Kwon, P.O., Chamberlin, H., Trogani, N., Xu, H., and Cohen, D. 1999. Histone deacetylase inhibition selectively alters the activity and expression of cell cycle proteins leading to specific chromatin acetylation and antiproliferative effects. J. Biol. Chem. 274: 34940-34947.

Sandor, V., Robbins, A.R., Robey, R., Myers, T., Sausville, E., Bates, S.E., and Sackett, D.L. 2000. FR901228 causes mitotic arrest but does not alter microtubule polymerization. Anticancer Drugs 11: 445-454.

Schumacher, J.M., Ashcroft, N., Donovan, P.J., and Golden, A. 1998. A highly conserved centrosomal kinase, AIR-1, is required for accurate cell cycle progression and segregation of developmental factors in Caenorhabditis elegans embryos. Development 125: 4391-4402.

Shin, H.J., Baek, K.H., Jeon, A.H., Kim, S.J., Jang, K.L., Sung, Y.C., Kim, C.M., and Lee, C.W. 2003. Inhibition of histone deacetylase activity increases chromosomal instability by the aberrant regulation of mitotic checkpoint activation. Oncogene 22: 3853-3858.

Shindo, M., Nakano, H., Kuroyanagi, H., Shirasawa, T., Mihara, M., Gilbert, D.J., Jenkins, N.A., Copeland, N.G., Yagita, H., and Okumura, K. 1998. cDNA cloning, expression, subcellular localization, and chromosomal assignment of mammalian aurora homologues, aurora-related kinase (ARK) 1 and 2. Biochem. Biophys. Res. Commun. 244: 285-292.

Sorrentino, R., Libertini, S., Pallante, P.L., Troncone, G., Palombini, L., Bavetsias, V., Spalletti-Cernia, D., Laccetti, P., Linardopoulos, S., Chieffi, P., et al. 2005. Aurora B overexpression associates with the thyroid carcinoma undifferentiated phenotype and is required for thyroid carcinoma cell proliferation. J. Clin. Endocrinol. Metab. 90: 928-935.

Steen, R.L., Cubizolles, F., Le Guellec, K., and Collas, P. 2000. A kinase-anchoring protein (AKAP) 95 recruits human chromosome-associated protein (hCAP)-D2/Eg7 for chromosome condensation in mitotic extract. J. Cell Biol. 149: 531-536.

Syka, J.E., Marto, J.A., Bai, D.L., Horning, S., Senko, M.W., Schwartz, J.C., Ueberheide, B., Garcia, B., Busby, S., Muratore, T., et al. 2004. Novel linear quadrupole ion trap/FT mass spectrometer: Performance characterization and use in the comparative analysis of histone $\mathrm{H} 3$ post-translational modifications. J. Proteome Res. 3: 621-626.

Taddei, A., Maison, C., Roche, D., and Almouzni, G. 2001. Reversible disruption of pericentric heterochromatin and centromere function by inhibiting deacetylases. Nat. Cell Biol. 3: 114-120.

Takahashi, T., Futamura, M., Yoshimi, N., Sano, J., Katada, M., Takagi, Y., Kimura, M., Yoshioka, T., Okano, Y., and Saji, S. 2000. Centrosomal kinases, HsAIRK1 and HsAIRK3, are overexpressed in primary colorectal cancers. Ipn. J. Cancer Res. 91: 1007-1014

Turner, B.M. 2000. Histone acetylation and an epigenetic code. Bioessays 22: 836-845.

Valls, E., Sanchez-Molina, S., and Martinez-Balbas, M.A. 2005. Role of histone modifications in marking and activating genes through mitosis. J. Biol. Chem. 280: 42592-42600.

Wade, P.A., Pruss, D., and Wolffe, A.P. 1997. Histone acetylation: Chromatin in action. Trends Biochem. Sci. 22: 128132.

Warrener, R., Beamish, H., Burgess, A., Waterhouse, N.J., Giles, N., Fairlie, D., and Gabrielli, B. 2003. Tumor cell-selective cytotoxicity by targeting cell cycle checkpoints. FASEB J. 17: 1550-1552.

Wei, Y., Yu, L., Bowen, J., Gorovsky, M.A., and Allis, C.D. 1999.
Phosphorylation of histone H3 is required for proper chromosome condensation and segregation. Cell 97: 99-109.

Wen, Y.D., Cress, W.D., Roy, A.L., and Seto, E. 2003. Histone deacetylase 3 binds to and regulates the multifunctional transcription factor TFII-I. J. Biol. Chem. 278: 1841-1847.

Wilson, A.J., Byun, D.S., Popova, N., Murray, L.B., L'Italien, K., Sowa, Y., Arango, D., Velcich, A., Augenlicht, L.H., and Mariadason, J.M. 2006. HDAC3 and other class I HDACs regulate colon cell maturation and $\mathrm{p} 21$ expression and are deregulated in human colon cancer. J. Biol. Chem. 281: 13548-13558.

Wong, C.F., Guminski, A., Saunders, N.A., and Burgess, A.J. 2005. Exploiting novel cell cycle targets in the development of anticancer agents. Curr. Cancer Drug Targets 5: 85-102.

Xiao, H., Hasegawa, T., and Isobe, K. 1999. Both Sp1 and Sp3 are responsible for $\mathrm{p} 21$ waf1 promoter activity induced by histone deacetylase inhibitor in NIH3T3 cells. J. Cell. Biochem. 73: 291-302.

Yang, W.M., Tsai, S.C., Wen, Y.D., Fejer, G., and Seto, E. 2002. Functional domains of histone deacetylase-3. J. Biol. Chem. 277: 9447-9454.

Yao, Y.L., Yang, W.M., and Seto, E. 2001. Regulation of transcription factor YY1 by acetylation and deacetylation. Mol. Cell. Biol. 21: 5979-5991.

Yu, J., Li, Y., Ishizuka, T., Guenther, M.G., and Lazar, M.A. 2003. A SANT motif in the SMRT corepressor interprets the histone code and promotes histone deacetylation. EMBO $T$. 22: 3403-3410.

Zeitlin, S.G., Shelby, R.D., and Sullivan, K.F. 2001. CENP-A is phosphorylated by Aurora B kinase and plays an unexpected role in completion of cytokinesis. J. Cell Biol. 155: 11471157.

Zhang, J., Kalkum, M., Chait, B.T., and Roeder, R.G. 2002. The N-CoR-HDAC3 nuclear receptor corepressor complex inhibits the JNK pathway through the integral subunit GPS2. Mol. Cell 9: 611-623.

Zhang, C., Richon, V., Ni, X., Talpur, R., and Duvic, M. 2005a. Selective induction of apoptosis by histone deacetylase inhibitor SAHA in cutaneous T-cell lymphoma cells: Relevance to mechanism of therapeutic action. J. Invest. Dermatol. 125: 1045-1052.

Zhang, X., Ozawa, Y., Lee, H., Wen, Y.D., Tan, T.H., Wadzinski, B.E., and Seto, E. 2005b. Histone deacetylase 3 (HDAC3) activity is regulated by interaction with protein serine/ threonine phosphatase 4. Genes \& Dev. 19: 827-839. 


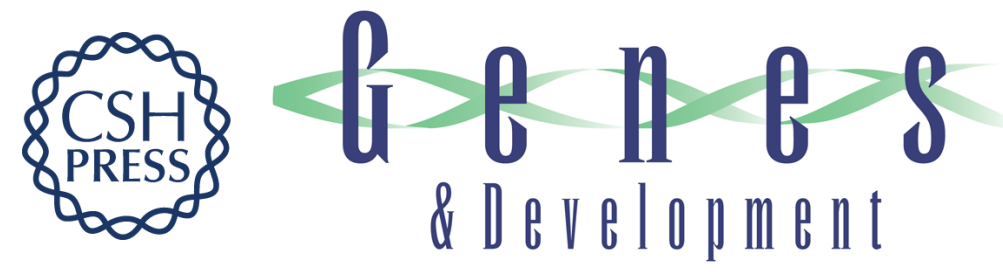

\section{A novel histone deacetylase pathway regulates mitosis by modulating Aurora B kinase activity}

Yun Li, Gary D. Kao, Benjamin A. Garcia, et al.

Genes Dev. 2006, 20:

Access the most recent version at doi:10.1101/gad.1455006

Supplemental http://genesdev.cshlp.org/content/suppl/2006/09/18/20.18.2566.DC1
Material

References This article cites 89 articles, 40 of which can be accessed free at:

http://genesdev.cshlp.org/content/20/18/2566.full.html\#ref-list-1

License

Email Alerting

Receive free email alerts when new articles cite this article - sign up in the box at the top

Service

right corner of the article or click here.

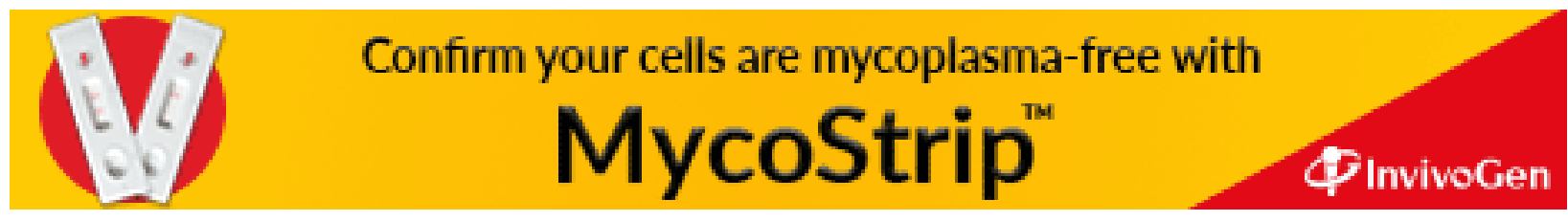

